\title{
The Association between Prothrombin Gene G20210A and Factor V Leiden Mutation in Women with Complications of Pregnancy in Baghdad Province

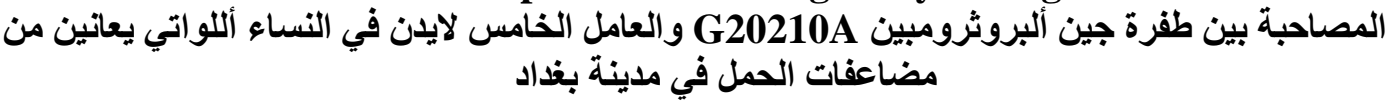

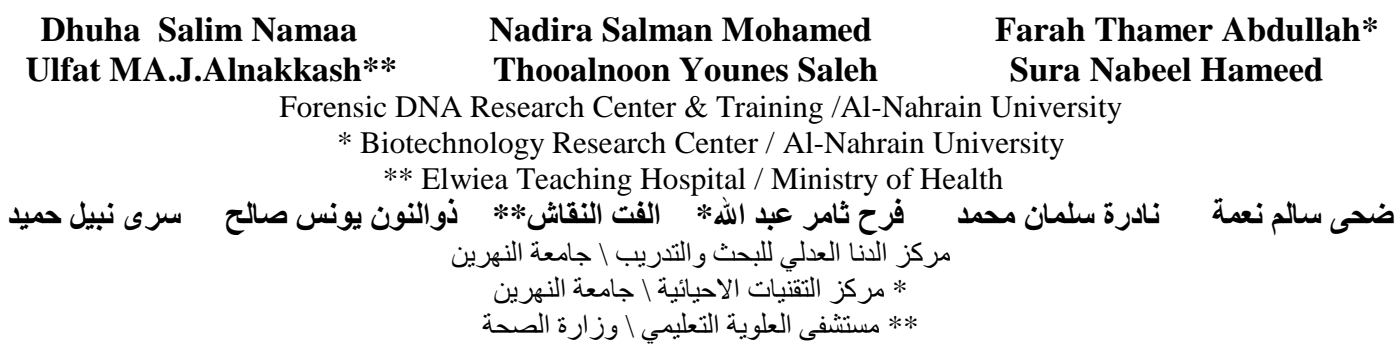

Nadira Salman Mohamed

Thooalnoon Younes Saleh Forensic DNA Research Center \& Training /Al-Nahrain University * Biotechnology Research Center / Al-Nahrain University ** Elwiea Teaching Hospital / Ministry of Health

E-mail: Dhuha.salim @yahoo.com

Abstract

Factor V Leiden (FVL) (G1691A) and prothrombin gene (G20210A) mutations are the most common inherited forms of thrombophilia. The main objective of this study is to analyze the association between inherited thrombophilia FVL mutation and prothrombin G20210A mutation and recurrent pregnancy loss (RPL) among women suffering from complications of pregnancy. The study included 40 buccal swab samples collected from women at the reproductive age complications; abruption placenta $12.5 \%$, dead fetal 37.5\%, and recurrent spontaneous abortions (RSA) $50 \%$ in comparison with 30 women who had one or more normal pregnancies from Elwiyah Obstetric teaching hospital through the period from mid of September 2014 to the mid of March 2015. The median age of patients was 32 years (range: 1942 years) while for the control group, it was 28 years (range: 17-41 years). Out of 40 women, $65 \%$ had one pregnancy loss and $35 \%$ for more than two previous pregnancy losses. According to the time of pregnancy losses, 22(55\%) women had early pregnancy loss (EPL), and 18 (45\%) women had Late Pregnancy Loss (LPL). For FVL mutation detection the restriction fragment length polymorphism (RFLP) was used. DNA fragment of interest was amplified by PCR and then subjected to digestion by MnlI specific restriction enzyme. For prothrombin G20210A mutation detection different PCR products were generated using a set of primers in A/A, G/G, A/G alleles. Out of the 70 samples tested for FVL mutation no homozygous FVL mutation was detected and Prothrombin gene mutation G20210A was totally absent among patient and control.

Key words: gene polymorphism, factor V Leiden, Prothrombin gene, obstetrical complications, abortion

(الملخص

تعد الطفرات الوراثية الحاصلة في جين العامل الخامس لايدن (G1691A) (GVL) وجين البروثرومبين (G20210A) هي من أكثر

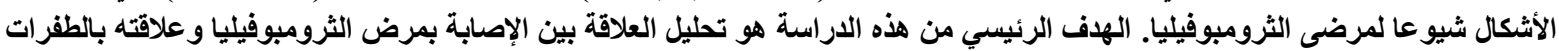

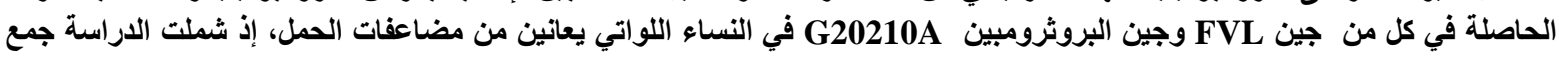

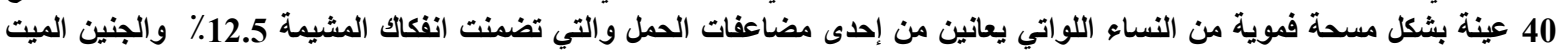

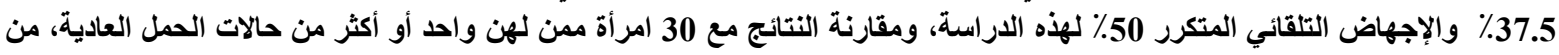

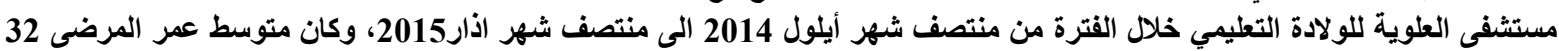

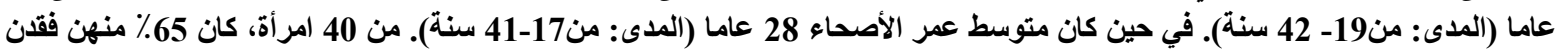

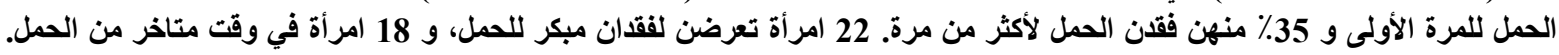

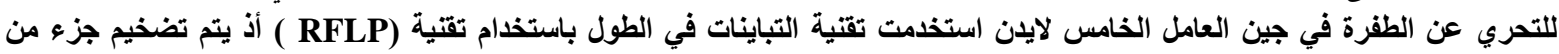

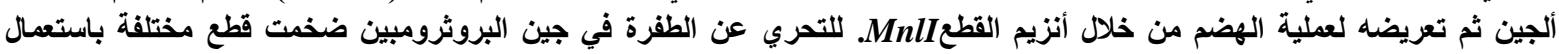

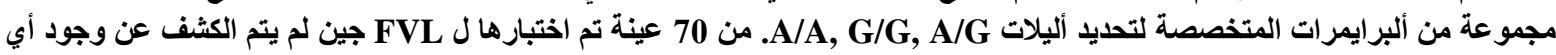

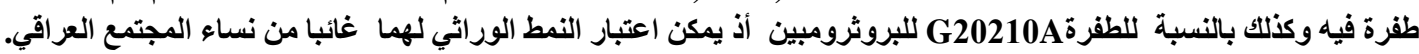

الكلمة الدالة : تعدد الأثكال الجيني، جين العامل الخامس لايدن، جين ألبروثرومبين، مضاعفات الحمل، الإجهاض 


\section{Introduction}

Recurrent pregnancy loss (RPL) represents a major health problem with two to three or more losses in up to $5 \%$ of women of reproductive age and is actually one of the most common causes of female sterility [1]. Thrombophilia, both acquired and hereditary, has been implicated in the increased susceptibility to adverse pregnancy outcomes such as fetal loss recurrent spontaneous abortions (RSA), abruption placenta, intrauterine growth restriction (IUGR) and pre-eclampsia [2]. Hereditary thrombophilia is a genetic disorder of blood coagulation resulting in an unusual hypercoagulation state, which in turn can result in abnormal implantation and may manifest as spontaneous loss [3].Genetic thrombosis risk factors include a sequence variant in the prothrombin $(20210 \mathrm{G}>\mathrm{A})$ and factor V Leiden $(1691 \mathrm{G}>\mathrm{A})$ genes. The functional consequence of the mutation that occurs is an impaired in activation of Factor V (also known as "activated protein C resistance"), Factor V Leiden is a single point mutation involving a guanine to adenine transition at position 1691 in exon 10 of the factor $\mathrm{V}$ gene, which leads to the synthesis of a variant factor $\mathrm{V}$ molecule. A FVL mutation resulting in a substitution of Glu to Arg at position 506 in the protein prevents cleavage of factor V at this site by APC and thus results in a delay of inactivation. As a result, clotting becomes less inhibited [4] resulting in increased thrombin generation. The second most frequent thrombophilia is a single nucleotide substitution (G20210A) in the promoter region of the gene for the key coagulation factor, prothrombin. This prothrombin gene mutation (PGM) results in an increase in the concentration of prothrombin [5]. It is determined that a variant of coagulation factor $\mathrm{V}$, designated as factor $\mathrm{V}$ Leiden, is basically a genetic polymorphism. This is a SNP polymorphism in the 506th cod on, which triplet CGA for arginine replaces the CAA triplet for glutamine. Under normal conditions, APC proteinbinds to factor $\mathrm{V}$ and cuts it into two inactive fragments. It is determined that the Leiden variant is resistant to APC protein, which prolongs the action of factor V. The result is a continuation of prothrombin activation and continuously maintain coagulation cascade [6-7]. Its frequency in European populations is $1-5 \%$, while it is very rare in people of African or Asiatic origin, this polymorphism is almost absent. It is estimated that this polymorphism originated 21- 24000 years ago [6-7].

Factor V Leiden and prothrombin G20210a mutations have been identified as high risk factors for venous thromboembolism (VTE) among Caucasians. In fact, the relative risk of venous thrombosis is increased approximately 4- to 8-fold in individuals who are heterozygous for the FVL mutation and up to 80-fold in individuals who are homozygous [7-8] .The prothrombin G20210A mutation increases the relative risk of venous thrombosis by approximately three fold [9].

The prothrombin G20210A mutation involves guanine to adenine substitution at nucleotide 20210 of the prothrombin gene [10]. The mutation is associated with an increased plasma concentration of prothrombin, which leads to an increased potential for thrombin generation [11]. The main objective of this study is to analyze the association between inherited thrombophilia FVL mutation and prothrombin G20210A mutation with RPL frequency.

\section{Materials and Methods}

\section{Sample collection (Buccal swab)}

Samples were collected from 40 women who had one of the above-mentioned obstetrical complications (abruption placenta, fetal growth retardation, and stillbirth) and 30 women who had one or more normal pregnancies from Elwiyah Obstetric teaching hospital through the period from mid of September 2014 to the mid of March 2015, the volunteers recruited were asked to rinse their mouth with tap water, 30 sec before sampling of Buccal swabs, to avoid the contamination as a result of food particles. For each individual, both sides of buccal mucosa were wiped with a cotton swab for $15 \mathrm{sec}$.

\section{Detection of FVL and prothrombin G20210A mutations}

DNA was extracted using organic phenol-chlorophorm method with modification [12]. The concentration of DNA sample was determined using the Nano Drop ND-1000 spectrophotometer (Nano Drop Technology. Detection of FVL and prothrombin G20210A mutations was based on examination the size of the polymerase chain reaction (PCR) products following DNA amplification of the target sequence of the factor $\mathrm{V}$ gene and factor II gene respectively. Factor V Leiden mutation detection was done by performing PCR-restriction fragment length polymorphism (RFLP) with MnlI specific restriction enzyme while allele-specific PCR was done to detect prothrombin G20210A mutation. The following primers were used according to [13]. Factor $\mathrm{V}$ Leiden Mutation detection by FVA 5' GGA ACA ACA CCA TGA TCA GAG CA -3', and FVB 5' TAG CCA 
GGA GAC CTA ACA TGT TC -3'. The prothrombin G20210A mutation detection by PRC 5' CTC CAA ACT GAT CAA TGA CCT TC -3' PFC 5' TCT AGA AAC AGT TGC CTG GCA -3' for common gene (c) produce $220 \mathrm{bp}$, Mismatched in one nucleotide in antisense primers were used to amplify both mutant (M) $340 \mathrm{bp}$, and normal (N) products 340 bp, PRN 5' CAC TGG GAG CAT TGA GGC AC -3', PRM 5' CAC TGG GAG CAT TGA GGC AT -3 primers sets. Two reaction sets was performed for each sample (Normal reaction contain: 0.5 $\mu \mathrm{l}$ PFC primer, $0.5 \mu \mathrm{l}$ PRC primer, $0.5 \mu \mathrm{l}$ PRN12.5 $\mu \mathrm{l}$ of $2 \mathrm{X}$ Master mix, $6 \mu l$ nuclease free water $\mu \mathrm{l}, 5 \mu \mathrm{l}$ template DNA), and (Mutant reaction contain: $0.5 \mu$ PFC primer, $0.5 \mu$ PRC primer, $0.5 \mu l$ PRM primer, $12.5 \mu \mathrm{l}$ of $2 \mathrm{X}$ Master mix, $6 \mu 1$ nuclease free water $\mu 1,5 \mu \mathrm{l}$ template DNA). The amplification cycle for both FVL and prothrombin G20210A mutation detection was optimized for several trial till reach to the optimal condition as the following: 1- pre-denaturation at $95^{\circ} \mathrm{C} 5$ minutes,2- secondary denaturation at $94^{\circ} \mathrm{C} 15$ seconds,3annealing at $64^{\circ} \mathrm{C}$ for $\mathrm{FVL}$, and at $62^{\circ} \mathrm{C}$ for prothrombin gene for $15 \mathrm{sec}$, 4-extention at $72^{\circ} \mathrm{C} 30 \mathrm{sec}$ (steps 2 4 was repeated for 40 cycles), 5 -final extension at $72^{\circ} \mathrm{C}$ for 1 minute and holding at $4^{\circ} \mathrm{C}$. After the PCR-RFLP and allele-specific PCR were performed, $7.0 \mu \mathrm{l}$ of the sample products were electrophoresed in a $3 \%$ agarose gel. The DNA ladder and samples were run at $70 \mathrm{~V}$ for 120 minutes. Finally, the bands were visualized using an image analyzer. Detection of FVL mutation involves the amplification of a $287 \mathrm{bp}$-long fragment, which yields in the production of various numbers of fragments after restriction with $0.5 \mu \mathrm{l} \mathrm{MnlI}, 0.5 \mu \mathrm{l}$ Bovine serum albumin, $2 \mu 1$ of $10 \mathrm{X}$ buffer, and $10 \mu \mathrm{l}$ of PCR products of FVL gene. Normal alleles with G/G at nucleotide 1691 yielded the following 3 fragments: $37 \mathrm{bp}, 93 \mathrm{bp}$, and $157 \mathrm{bp}$. As FVL mutation abolishes the MnlI restriction site, a homozygous A/A yields only $130 \mathrm{bp}$ and $157 \mathrm{bp}$ fragments. In heterozygous alleles with genotype G/A, all $37 \mathrm{bp}, 93 \mathrm{bp}, 130 \mathrm{bp}$, and $157 \mathrm{bp}$ fragments are produced. For prothrombin G20210A mutation detection, electrophoresis yields a $220 \mathrm{bp}$ fragment and a $340 \mathrm{bp}$ fragment in Normal (N) and 220bp in mutant $(\mathrm{M})$ reactions respectively when a normal $\mathrm{G} / \mathrm{G}$ allele is present at nucleotide G20210A. In homozygous mutant $\mathrm{A} / \mathrm{A}$ alleles, both $220 \mathrm{bp}$ and $340 \mathrm{bp}$ fragments are produced in $\mathrm{M}$ reaction while none is produced in $\mathrm{N}$ reaction. On the other hand, heterozygous $\mathrm{G} / \mathrm{A}$ alleles yield $219 \mathrm{bp}$ and $340 \mathrm{bp}$ fragments in $\mathrm{M}$ reaction and a $340 \mathrm{bp}$ fragment in $\mathrm{N}$ reaction.

\section{Results and discussion}

During the study, taking into account the age of the women, the obstetrical complications in pregnancy and frequency of pregnancy loss of embryos, and studying the impact of these factors on the rate of emergence of both FVL and prothrombin G20210A mutation. The obstetrical complications showed in Figure (1), abruption placenta represented $12.5 \%$, while dead fetal was represented $37.5 \%$, and the recurrent spontaneous abortions (RSA) was represented $50 \%$ of the subject study.The median age of the patients women was 32 years (range: 19-42 years) while median age of the control group was 28 years (range: 17-41 years). Out of 40 women, $65 \%$ had one pregnancy losses and 35\% for more than two previous pregnancy losses. According to the time of pregnancy losses, $22(55 \%)$ women had Early Pregnancy Loss (EPL) $<7$ weeks, and 18 (45\%) women had Late Pregnancy Loss (LPL) $>7$ weeks as shown in Figure 2. The association of inherited markers of thrombophilia in a 40 pregnant Iraqi women with a history of multiple pregnancy loss was conducted. Out off 70 tested cases all had normal allele while no homozygote or heterozygous FVL mutation were detected the results was showed in Figure (3 and 4).

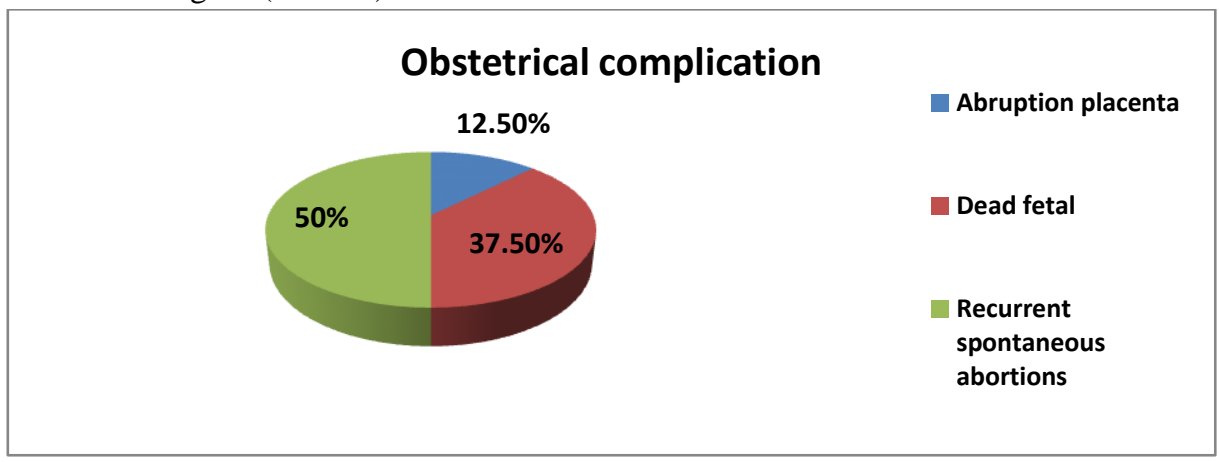

Fig. (1): The percentage of the obstetrical complication in 40 women 


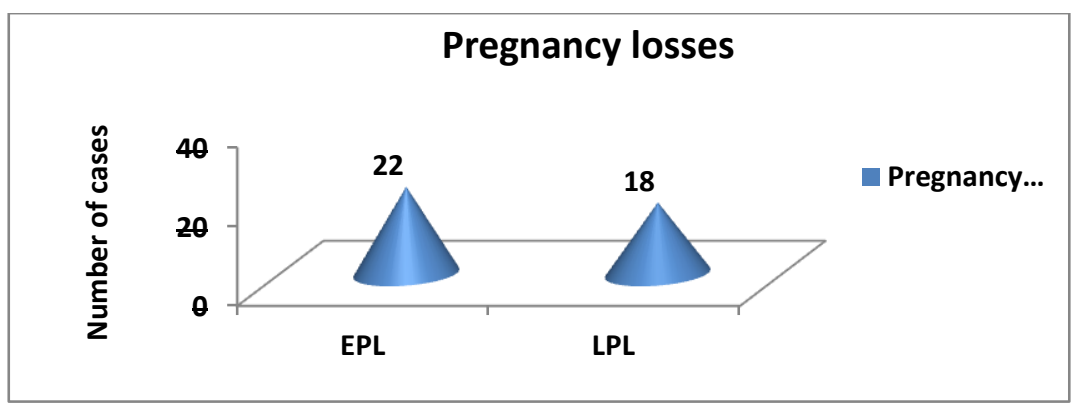

Fig. (2): The number of women who had the early pregnancy loss, and the late pregnancy loss according to time of pregnancy losses.

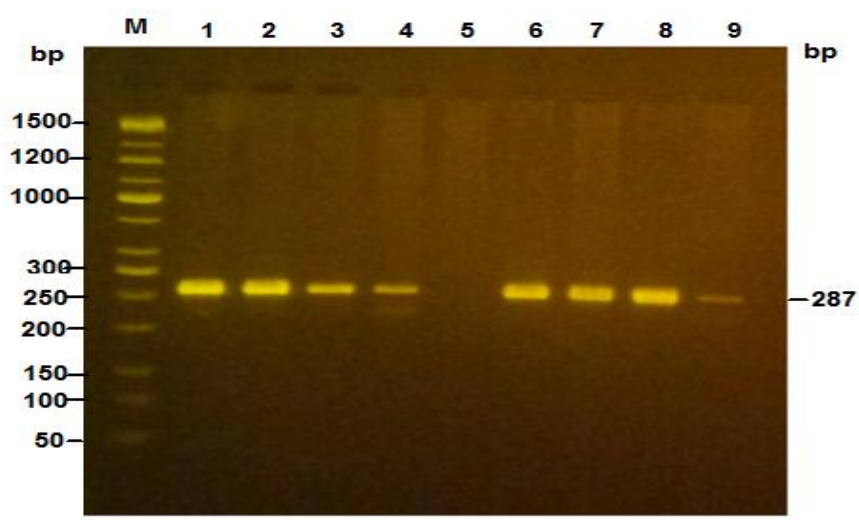

Fig. (3): Electrophoresis analysis of PCR product FVL gene fragment 287 bp ,using $2 \%$ Agarose stained with red safe DNA dye and electrophoresed by $3 \mathrm{vol} / \mathrm{cm}$ in TBA buffer, Lane M-50 bp DNA ladder.Lane $(1,2,3,4$,$) show samples of healthy group and (6,7,8,9$,$) sample of patients .$

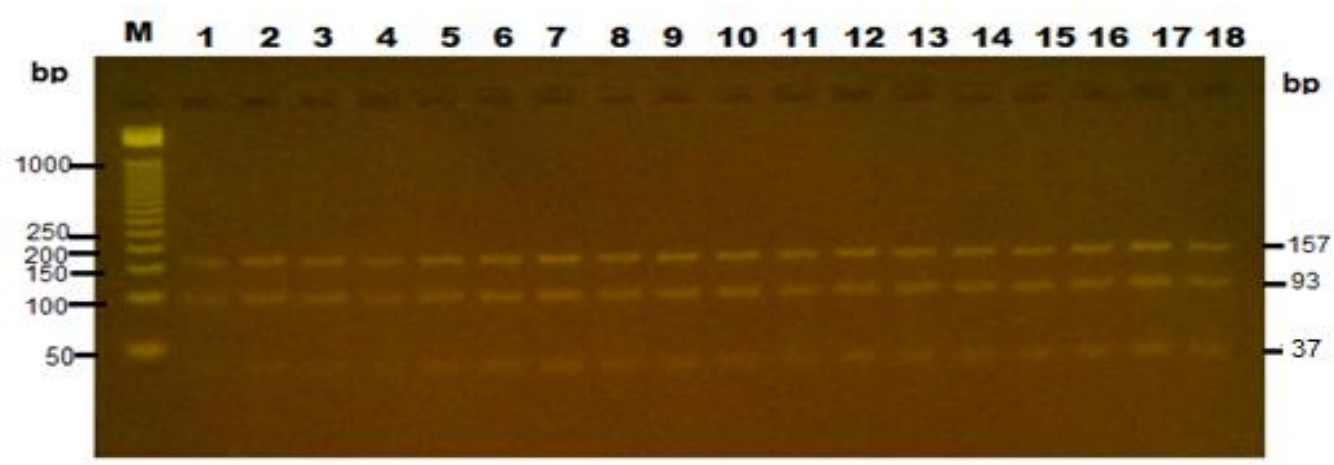

Fig. (4): The gel-electrophoresis result of RFLP using 3\% Agarose stained with red safe DNA dye and electrophoresed by 3vol/cm in TBA buffer. Lane M-50 bp DNA ladder, Lane $(1,3,5,7,10,11,14,16,17)$ patient sample and lane $(2,4,6,8,9,12,13)$ healthy people. PCR product restricted with $M n I I$ restriction enzyme showed normal allele G/G. 


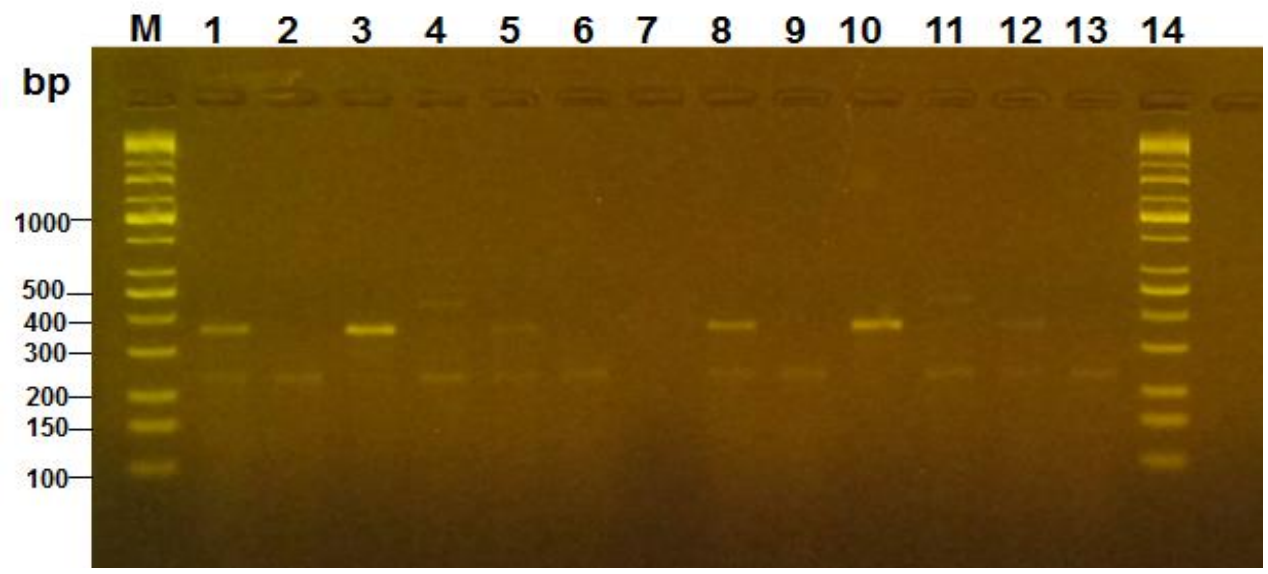

Fig. (5): The gel-electrophoresis result of prothrombin G20210A mutation in $3 \%$ agarose stained with red safe DNA dye and electrophoresed by 3vol/cm in TBA buffer. Lane M-100 bp DNA ladderelectrophoresis, lane $1,3,5,8,10,12$ showed Normal reaction result $(220 \mathrm{bp}$, and340bp for sample 11,3,15,8,11,33,) respectively lane 2,4,6,9,11,13 showed Mutant reaction result $(220$ bp for sample 11,3,15,8,11,33, $)$ respectively.

Also no prothrombin G20210A mutation was detected in any patients or control groups, which indicates that FVL and G20210 prothrombin gene mutations are infrequent in Iraqi women as mention as in figure (5). Our findings were very closed to Abdullah's et al .,[12] study results that was conducted on healthy Indians in Malaysia , they was reported (5.6\%) heterozygous for FVL mutation, and agree with Vora et al.,[13] study on Indian people as they found that (3.4\%) homozygous FVL mutation were positive for factor V Leiden mutation compared to $1 \%$ of controls. These findings are in complete agreement with previous reports that found prothrombin G20210A mutation to be totally absent among non-Caucasians patients, Ahmed et al.,[14].Greer [15] study on Caucasian population was found that the inherited thrombophilia is common in the Caucasian population with a prevalence of up to $15 \%$ Our result was indicated that there is no association between the prothrombin G20210A mutation and pregnancy loss, and this result is agrees with Robert et al., [16], and with Sharma et al [17] that the factor V Leiden and G20210 prothrombin gene mutations are infrequent in Indian patients with portal vein thrombosis PVT. Thus, these mutations are unlikely to be responsible for PVT in the Indian population. We concluded that there was no association between the prothrombin G20210A mutation and any individual obstetric complication, including pregnancy loss, preeclampsia, abruption, and SGA neonates in Iraqi patients. This low-risk results among studies may explained by the different ethnic groups that found in Iraqi population. The variability of result in different study appeared due to the small size of samples that have been used to conduct these studies and the diversity of ethnic groups. Each of these factors introduces potential bias. It is striking that the only large case-control study may be confident to find the association between the prothrombin G20210A mutation and SGA neonates.

\section{Conclusion}

This study indicated that FVL and G20210 prothrombin gene mutations are infrequent in Iraqi women.

\section{References}

1. Sarig, G., Younis, J.S., Hoffman, R., Lanir. N., Blumenfeld, Z., Brenner, B. (2002). Thrombophilia is common in women with idiopathic pregnancy loss and is associated with late pregnancy wastage. FertilSteril.77 (2):342-347.

2. Walker, I.D. (2000). Diagnostic Single Nucleotide Polymorphism Analysisof Factor V Leiden and Prothrombin 20210G>AA Comparison of the Nanogen Electronic MicroarrayWith Restriction Enzyme Digestion and the Roche Light Cycler. Thrombophilia in pregnancy .J ClinPathol; 53:573-80.

3. Younis, J.S., Ohel, G. Brenner. B. and Ben-Ami, M. (1997). Familial thrombophilia-the scientific rationale for thrombophylaxis in recurrent pregnancy loss. HumReprod. 12(7):1389-90.

4. Horne, M.D.K. and McCloskey, D.J. (2006). Factor V Leiden as a common genetic risk factor for venous thromboembolism. Journal of Nursing Scholarship.38:19.

5. Baglin, T., Gray, E., Greaves, M., Hunt, B.J., Keeling, D., Machin, S., Mackie, I., Makris, M., Nokes, T., Perry, D., Tait, R.C., Walker, I. and Watson, H. (2010). Clinical guidelines for testing for heritable thrombophilia. Br J Haematol.149 (2):209-220. 
6. Robertson, L., Wu, O., Langhorne, P., Twaddle, S., Clark, P., Lowe, G.D.O., et al. (2005).Thrombophilia in pregnancy: a systematic review. Br J Haematol.132: 171-196. Ho, W.K., Hankey, G.J., Quinlan, D.J., Eikelboo, J.W. (2006). Risk of recurrent venous thromboembolism in patients with common thrombophilia. Arch Intern Med. 166:729-36.

7. Libby, E.N., Booker, J. K, and Gulley, M.L. (2005). False-negative factor V Leiden genetic testing in a patient with recurrent deep venous thrombosis. Am J Haematol.81:284-289.

8. Schrijver, I., Marla, J. Lay, and Zehnder, J.L. (2003). Am J ClinPathol.119: 490-496.

9. Andreassi, M.G., Botto, N. and Maffei, S. (2006). Factor V Leiden, prothrombin G20210A substitution and hormone therapy: Indications for molecular screening. ClinChem Lab Med. 44:514-521.

10. League, S. and Hooper, W.C. (2005). Molecular diagnostics of inherited thrombosis. Clin Lab Sci.18:271-279.

11. Ghatak, S., Bose, R., kumaran, M. and Kumar, S.N. (2013)."A Simple Method of Genomic DNA Extraction from Human Samples for PCR-RFLP Analysis". Journal of bimolecular techniques. 24: 4.

12. Abdullah, W.Z., Kumaraguru, S., Ghazali, S. and Yusoff, N.M M. (2010). Factor V Leiden and Prothrombin G20210A Mutations among Healthy Indians in Malaysia. LABMEDICINE .Volume 41 Number 5: 284-287.

13. Vora, S., Shetty, S., Savi, V., Satokar, P. and Ghosh, k. (2008).Thrombophilia and unexplained pregnancy loss in Indian patients. The National Medical Journal of India. 21: 3.

14. Ahmed, R.P, Gupta P.K., Kannan, M., Choudhry, V.P., Saxena, R. (2003). Factor V Leiden-the commonest molecular defect in arterial and venous thrombophilia in India. Thromb Res.110:19-21.

15. Greer, I. (2003). Thrombophilia: implications for pregnancy outcome. Thrombosis Research.109:73-81.

16. Robert, M., Silver, M.D., Yuan Zhao, M.S, Catherine, Y., Spong, M.D., BahaSibai, M.D., GeorgeWendelJr, M.D., Katharine Wenstrom, M.D., Philip Samuels, M.D., Steve, N. Caritis, M.D., YoramSorokin, M.D., MenachemMiodovnik, M.D., Mary, J. O’Sullivan, M.D., Deborah Conway, M.D., Ronald, J., Wapner, M.D., and Eunice Kennedy, Shriver. (2010). Prothrombin Gene G20210A Mutation and Obstetric Complications. Obstet Gynecol. 115(1): 14-20.

17. Sharma, S., Kumar, S.I., Poddar,U., Yachha, S. K. and Aggarwal, R. (2006). Indian Factor V Leiden and prothrombin gene G20210A mutationsare uncommon in portal vein thrombosis in India. Journal of Gastroenterology. $25: 237$ 